\title{
Assessing genomic diversity and signatures of selection in Original Braunvieh cattle using whole-genome sequencing data
}

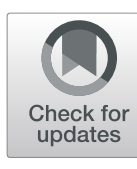

Meenu Bhati ${ }^{*}$ D, Naveen Kumar Kadri, Danang Crysnanto and Hubert Pausch

\begin{abstract}
Background: Autochthonous cattle breeds are an important source of genetic variation because they might carry alleles that enable them to adapt to local environment and food conditions. Original Braunvieh (OB) is a local cattle breed of Switzerland used for beef and milk production in alpine areas. Using whole-genome sequencing (WGS) data of 49 key ancestors, we characterize genomic diversity, genomic inbreeding, and signatures of selection in Swiss OB cattle at nucleotide resolution.

Results: We annotated 15,722,811 SNPs and 1,580,878 Indels including 10,738 and 2763 missense deleterious and high impact variants, respectively, that were discovered in 49 OB key ancestors. Six Mendelian trait-associated variants that were previously detected in breeds other than $\mathrm{OB}$, segregated in the sequenced key ancestors including variants causal for recessive xanthinuria and albinism. The average nucleotide diversity $\left(1.6 \times 10^{-3}\right)$ was higher in $\mathrm{OB}$ than many mainstream European cattle breeds. Accordingly, the average genomic inbreeding derived from runs of homozygosity $(\mathrm{ROH})$ was relatively low $\left(\mathrm{F}_{\mathrm{ROH}}=0.14\right)$ in the $49 \mathrm{OB}$ key ancestor animals. However, genomic inbreeding was higher in $\mathrm{OB}$ cattle of more recent generations $\left(\mathrm{F}_{\mathrm{ROH}}=0.16\right)$ due to a higher number of long (>1 Mb) runs of homozygosity. Using two complementary approaches, composite likelihood ratio test and integrated haplotype score, we identified 95 and 162 genomic regions encompassing 136 and 157 protein-coding genes, respectively, that showed evidence $(P<0.005)$ of past and ongoing selection. These selection signals were enriched for quantitative trait loci related to beef traits including meat quality, feed efficiency and body weight and pathways related to blood coagulation, nervous and sensory stimulus.

Conclusions: We provide a comprehensive overview of sequence variation in Swiss OB cattle genomes. With WGS data, we observe higher genomic diversity and less inbreeding in OB than many European mainstream cattle breeds. Footprints of selection were detected in genomic regions that are possibly relevant for meat quality and adaptation to local environmental conditions. Considering that the population size is low and genomic inbreeding increased in the past generations, the implementation of optimal mating strategies seems warranted to maintain genetic diversity in the Swiss OB cattle population.
\end{abstract}

\section{Introduction}

Following the domestication of cattle, both natural and artificial selection led to the formation of breeds with distinct phenotypic characteristics including morphological, physiological and adaptability traits [1]. With an increasing demand for animal-based food products, few breeds were intensively selected for high milk (e.g., Holstein, Brown Swiss) and beef (e.g., Angus) production. The predominant selection of cattle from specialized

\footnotetext{
* Correspondence: meenu.bhati@usys.ethz.ch

Animal Genomics, ETH Zürich, Zürich, Switzerland
}

breeds caused a sharp decline in the population size of local breeds [2, 3]. Although less productive under intensive production conditions, local breeds of cattle might carry alleles that enable them to adapt to local conditions. Therefore, local breeds represent an important genetic resource to facilitate animal breeding in the future under challenging and changing production conditions $[4,5]$. Characterizing the genetic diversity of local cattle breeds is important to optimally manage these genetic resources.

(c) The Author(s). 2020 Open Access This article is distributed under the terms of the Creative Commons Attribution 4.0 International License (http://creativecommons.org/licenses/by/4.0/), which permits unrestricted use, distribution, and reproduction in any medium, provided you give appropriate credit to the original author(s) and the source, provide a link to the Creative Commons license, and indicate if changes were made. The Creative Commons Public Domain Dedication waiver (http://creativecommons.org/publicdomain/zero/1.0/) applies to the data made available in this article, unless otherwise stated. 
The Swiss Original Braunvieh (OB) cattle breed is a dual purpose taurine cattle breed that is used for beef and milk production in alpine areas $[6,7]$. In transhumance, the cattle graze at alpine pastures (between 1000 and $2400 \mathrm{~m}$ above sea level) during the summer months and return to the stables for the winter months [7]. Mainly due to their strong and firm legs and claws, OB cattle are well adapted to the alpine terrain. Under extensive farming conditions, $\mathrm{OB}$ cattle may outperform specialized dairy breeds in terms of fertility, longevity and health status [8]. However, in the early 1960s, Swiss cattle breeders began inseminating $\mathrm{OB}$ cows with semen from US Brown Swiss sires to increase milk yield, reduce calving difficulties and improve mammary gland morphology of the Swiss OB cattle population [9]. The extensive cross-breeding of $\mathrm{OB}$ cows with Brown Swiss sires decreased the number of female OB calves entering the herd book to less than 2000 by mid 1990's [9] (Additional file 1). Since then, the Swiss OB population increased steadily, facilitated by governmental subsidies.

A number of studies investigated the genomic diversity and population structure of the Swiss $\mathrm{OB}$ cattle breed using either pedigree or microarray data $[9,10]$. In spite of the small population size, genetic diversity is higher in $\mathrm{OB}$ than many commercial breeds likely due to the use of many sires in natural mating and lower use of artificial insemination $[9,10]$. Genomic inbreeding and footprints of selection have been compared between $\mathrm{OB}$ and other Swiss cattle breeds using SNP microarray-derived genotypes [10]. Because the SNP microarrays were designed in a way that they interrogate genetic markers that are common in the mainstream breeds of cattle, they might be less informative for breeds of cattle that are diverged from the mainstream breeds [11]. Ascertainment bias is inherent in the resulting genotype data because rare, breed-specific, and less-accessible genetic variants are underrepresented among the microarrayderived genotypes [12]. This limitation causes observed allele frequency distributions to deviate from expectations which can distort population genetics estimates [13].

With the availability of whole genome sequencing (WGS), it has become possible to discover sequence variant genotypes at population scale [14]. While sequence variant genotypes might be biased toward the reference allele, this reference bias is less of a concern when the sequencing coverage is high [15]. According to Boitard et al. 2016 [16], WGS data facilitate detecting selection signatures at higher resolution than SNP microarray data. Moreover, the WGS-based detection of runs of homozygosity $(\mathrm{ROH})$ is more sensitive for short $\mathrm{ROH}$ that are typically missed using SNP microarray-derived genotypes.
In the present study, we analyze more than 17 million WGS variants of 49 key ancestors of the Swiss OB cattle breed that were sequenced to an average fold-coverage of 12.75 per animal [17]. These data enabled us to assess genomic diversity and detect signatures of past or ongoing selection in the breed at nucleotide resolution. Moreover, we estimate genomic inbreeding in the population using runs of homozygosity.

\section{Results}

\section{Overview of genomic diversity in OB cattle}

We annotated 15,722,811 biallelic SNPs and 1,580,878 Indels that were discovered in $49 \mathrm{OB}$ cattle [17]. The average genome wide nucleotide diversity within the $\mathrm{OB}$ breed was $0.001637 / \mathrm{bp}$. Among the detected variants, 546,419 (3.5\%) SNPs and 307,847 (19.5\%) Indels were found novel when compared to the $102,090,847$ polymorphic sites of the NCBI bovine dbSNP database version 150 .

Functional annotation of the polymorphic sites revealed that the vast majority of SNPs were located in either intergenic $(73.8 \%)$ or intronic regions $(25.2 \%)$. Only

Table 1 Number of SNPs and Indels in sequence ontology classes annotated using the VEP software

\begin{tabular}{lll}
\hline Sequence ontology class & SNP & Indel \\
\hline splice_acceptor_variant & 272 & 84 \\
splice_donor_variant & 273 & 71 \\
stop_gained & 580 & 16 \\
frameshift_variant & 0 & 1324 \\
stop_lost & 33 & 0 \\
start_lost & 106 & 4 \\
inframe_insertion & 0 & 290 \\
inframe_deletion & 0 & 440 \\
missense_variant & 47,429 & 0 \\
protein_altering_variant & 0 & 12 \\
splice_region_variant & 9553 & 1059 \\
stop_retained_variant & 45 & 2 \\
synonymous_variant & 58,387 & 0 \\
coding_sequence_variant & 166 & 125 \\
mature_miRNA_variant & 83 & 23 \\
5_prime_UTR_variant & 6744 & 600 \\
3_prime_UTR_variant & 30,716 & 4074 \\
non_coding_transcript_exon_variant & 6296 & 434 \\
intron_variant & $3,960,673$ & 422,764 \\
non_coding_transcript_variant & 24 & 25 \\
upstream_gene_variant & 526,000 & 56,715 \\
downstream_gene_variant & 454,753 & 51,672 \\
intergenic_variant & $10,620,678$ & $1,041,144$ \\
Total & $15,722,811$ & $1,580,878$ \\
\hline
\end{tabular}


$1 \%$ of SNPs $(160,707)$ were located in the exonic regions (Table 1). In protein-coding sequences, we detected 58 , 387, 47,249 and 1264 synonymous, missense, and high impact SNPs, respectively. According to the SIFT scoring, 10,738 missense SNPs were classified as likely deleterious to protein function (SIFT score $<0.05$ ). Among the high impact variants, we detected 580, 33, 106, 273 and 272 stop gain, stop lost, start lost, splice donor and splice acceptor variants, respectively. Deleterious and high impact variants were more frequent in the low than high allele frequency classes (Additional file 2).

The majority of 1,580,878 Indels were detected in either intergenic $(72.7 \%)$ or intronic $(26.7 \%)$ regions. Only $2213(0.14 \%)$ Indels affected coding sequences. Among these, 1499 were classified as high impact variants including 1324, 16, 4, 71 and 84 frameshift, stop gain, start lost, splice donor and splice acceptor variants, respectively. Similar to previous studies in cattle $[14,18]$, coding regions were enriched for Indels with lengths in multiples of three indicating that they are less likely to be deleterious to protein function than frameshift variants (Additional file 3).

\section{OMIA variants segregating in the $O B$ population}

We obtained genomic coordinates of 155 variants that are associated with Mendelian traits in cattle from the OMIA database to analyze if they segregate among the $49 \mathrm{OB}$ cattle. It turned out that six OMIA variants were also detected in the $49 \mathrm{OB}$ cattle including two variants in the MOCOS and SLC45A2 genes that are associated with severe recessive disorders (Additional file 4). Two OB key ancestor bulls born in 1967 and 1974 (ENA SRA sample accession numbers SAMEA4827662 and SAMEA4827664) were heterozygous carriers of a single base pair deletion (BTA24:g.21222030delC) in the MOCOS gene (OMIA 001819-9913) that causes xanthinuria in the homozygous state in Tyrolean grey cattle [19]. Another two OB key ancestor bulls (sire and son; ENA SRA sample accession numbers SAMEA4827659 and SAMEA4827645) that were born in 1967 and 1973 were heterozygous carriers of two missense variants in SLC45A2 (BTA20:g.39829806G > A and BTA20: g.39864148C $>$ T) that are associated with oculocutaneous albinism (OMIA 001821-9913) in Braunvieh cattle [20].

\section{Runs of homozygosity and genomic inbreeding}

Runs of homozygosity were analyzed in 33 OB animals that had an average sequencing depth greater than 10fold. We found $2044 \pm 79$ autosomal ROH per individual with a length of $179 \mathrm{~kb} \pm 17.6 \mathrm{~kb}$. The length of the $\mathrm{ROH}$ ranged from $50 \mathrm{~kb}$ (minimum size considered, see methods) to $5,025,959 \mathrm{bp}$. On average, $14.58 \%$ of the genome (excluding sex chromosome) was in $\mathrm{ROH}$
(Additional file 5). Average genomic inbreeding for the 29 chromosomes ranged from 11.5\% (BTA29) to $18.6 \%$ (BTA26) (Fig. 1a).

In order to study the demography of the $\mathrm{OB}$ population, we calculated the contributions of short, medium and long $\mathrm{ROH}$ to the total genomic inbreeding (Additional file 5). The medium-sized $\mathrm{ROH}$ were the most frequent class $(50.46 \%)$, and contributed most $(75.01 \%)$ to the total genomic inbreeding. While short $\mathrm{ROH}$ occurred almost as frequent (49.17\%) as medium-sized $\mathrm{ROH}$, they contributed only $19.52 \%$ to total genomic inbreeding (Fig. 1b \& c; Additional file 5). Long ROH were rarely $(0.36 \%)$ observed among the OB key ancestors and contributed little $(5.47 \%)$ to total genomic inbreeding. The number of long $\mathrm{ROH}$ was correlated $(r=0.77)$ with genomic inbreeding.

Genomic inbreeding $\left(\mathrm{F}_{\mathrm{ROH}}\right)$ was significantly $(P=$ 0.0002) higher in 20 animals born between 1990 and 2012 than in 13 animals born between 1965 and 1989 (0.16 vs. 0.14) (Additional file 6). The higher $\mathrm{F}_{\mathrm{ROH}}$ in animals born in more recent generations was mainly due to more long ( $>2 \mathrm{Mb} ; P=0.00004$ ) and medium-sized $\mathrm{ROH}(0.1-1 \mathrm{Mb} ; P=0.001)$ (Fig. 2).

\section{Signatures of selection}

We identified candidate signatures of selection using two complementary methods: the composite likelihood ratio (CLR) test and the integrated haplotype score (iHS) (Fig. 3a \& b). The CLR test detects 'hard sweeps' at genomic regions where beneficial adaptive alleles recently reached fixation [21]. The iHS detects 'soft sweeps' at genomic regions where selection for beneficial alleles is still ongoing [22, 23]. We detected 95 and 162 candidate regions of signatures of selection $(P<0.005)$ using CLR and iHS, respectively, encompassing $12.56 \mathrm{Mb}$ and 12.48 $\mathrm{Mb}$ (Additional file 7; Additional file 8). These candidate signatures of selection were not evenly distributed over the genome (Fig. 3c). Functional annotation revealed that 136 and 157 protein-coding genes overlapped with 50 and 86 candidate regions from CLR and iHS analyses, respectively. All other candidate signatures of selection were located in intergenic regions. Closer inspection of the top selection regions of both analyses revealed that 16 CLR candidate regions overlapped with 25 iHS candidate regions on chromosomes 5, 7, 11, 14, 15, 17 and 26 (Fig. 3c) encompassing 35 coding genes (Additional file 9).

\section{Top candidate signatures of selection}

On chromosome 11, we identified 12 and 36 candidate regions of selection using CLR and iHS analyses, respectively. The top CLR candidate region $\left(P_{C L R}=3.1 \times\right.$ $10^{-5}$ ) was located on chromosome 11 between $66 \mathrm{Mb}$ and $68.5 \mathrm{Mb}$ (Fig. 4a) and it encompassed 24 protein- 

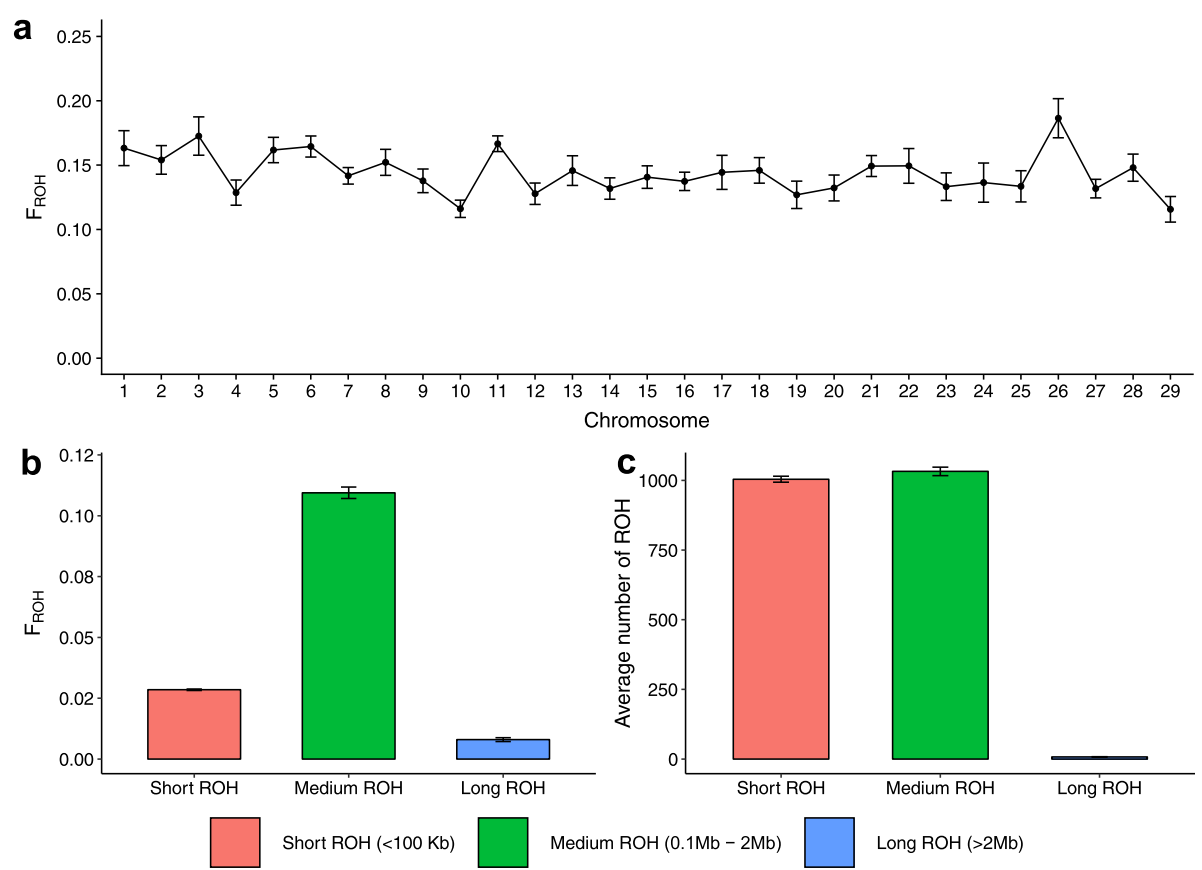

Fig. $1 \mathrm{ROH}$ in $33 \mathrm{OB}$ cattle with average sequencing depth greater than 10-fold. a Average genomic inbreeding and corresponding standard error for the 29 autosomes. b Average genomic inbreeding $\left(F_{\mathrm{ROH}}\right)$ calculated from short $(50-100 \mathrm{~kb})$, medium $(0.1-2 \mathrm{Mb})$ and long $(>2 \mathrm{Mb}) \mathrm{ROH}$. (c) Average number of short, medium and long $\mathrm{ROH}$

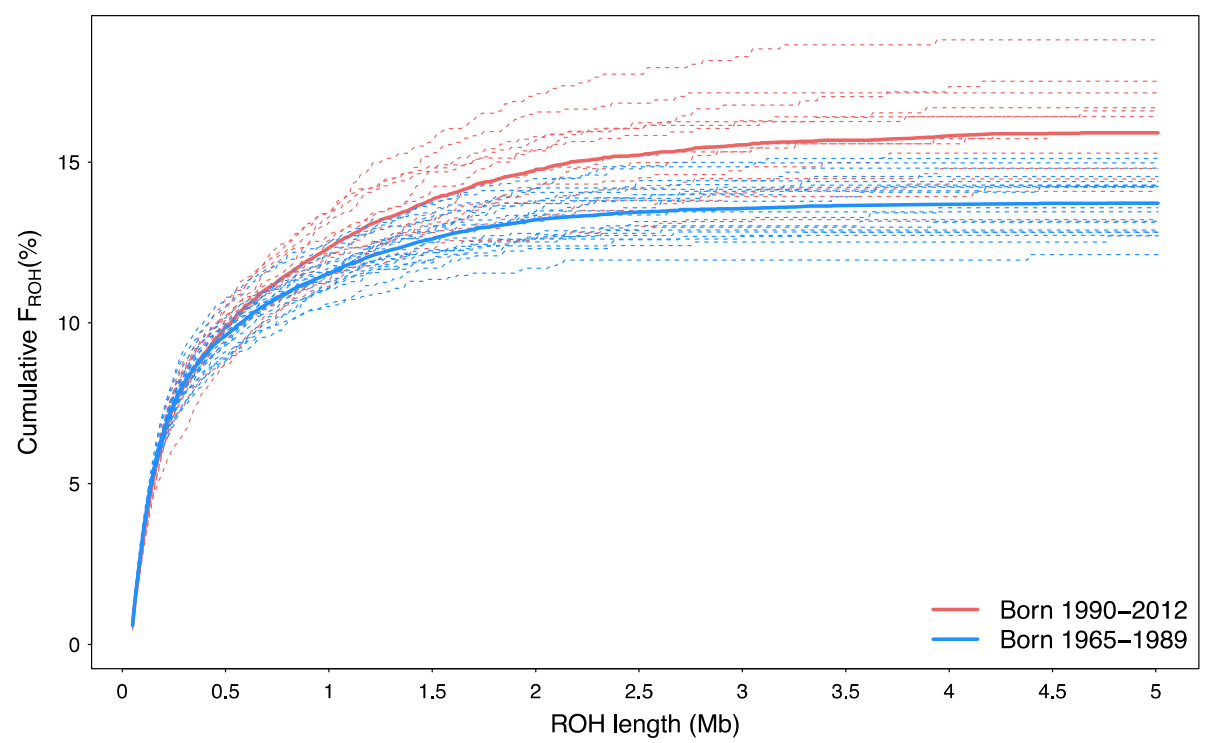

Fig. 2 Cumulative genomic inbreeding (\%) in animals born between 1965 and 1989 (blue lines) and 1990-2012 (red lines) from ROH sorted on length and binned in windows of $10 \mathrm{~kb}$. Thin dashed lines represent individuals and thick solid lines represent the average cumulative genomic inbreeding of the two groups of animals 

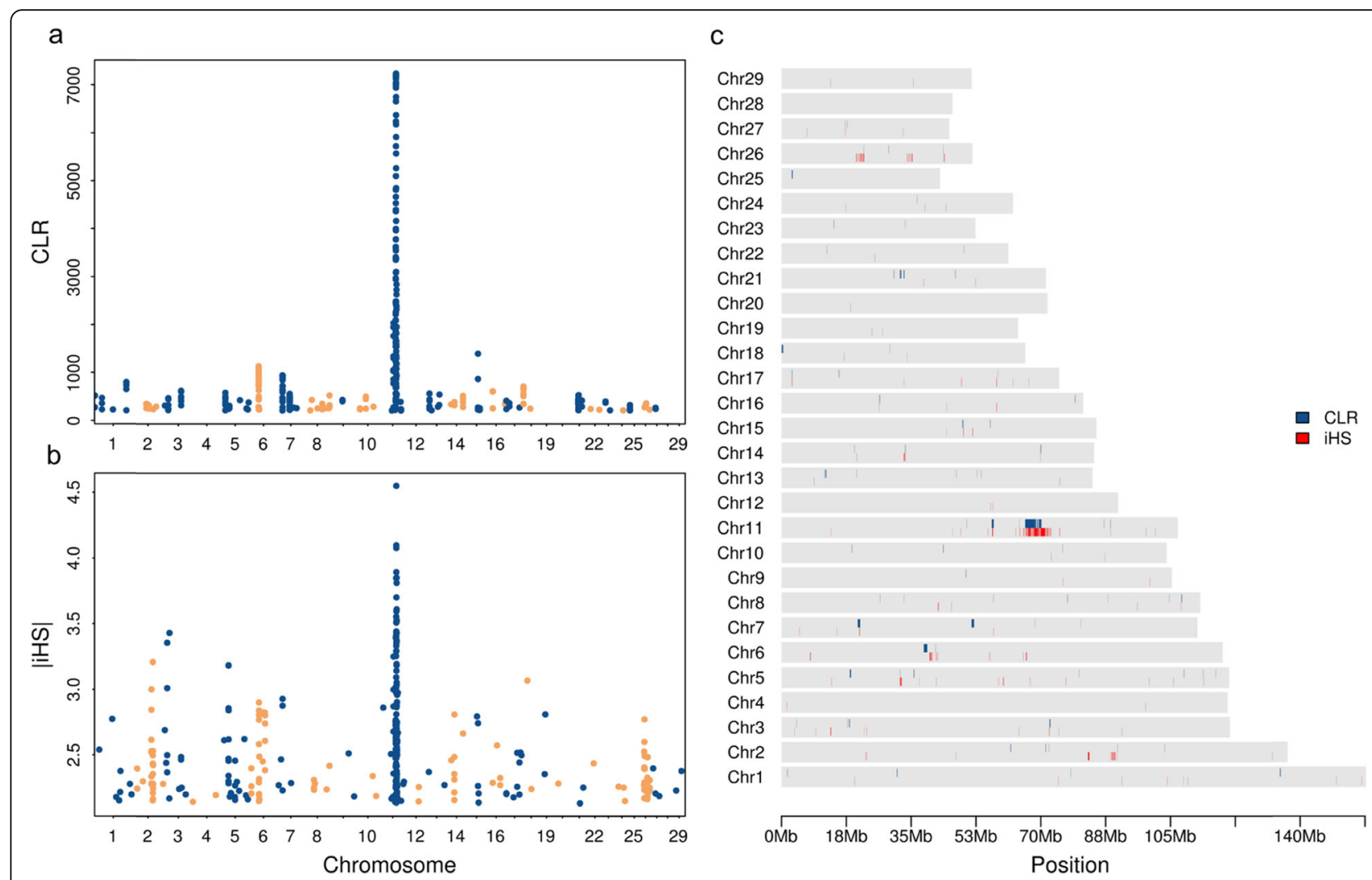

Fig. 3 Genome wide distribution of top $0.5 \%$ signatures of selection from CLR (a) and iHS (b) analyses and their overlap (c). Each point represents a non-overlapping window of $40 \mathrm{~kb}$ along the autosomes

coding genes (Additional file 7). The same region was also in $\mathrm{ROH}$ in $77 \%$ of 33 animals that were sequenced at high coverage. The peak of this top CLR region was located between 67.5 and $68.2 \mathrm{Mb}$ and it contained several adjacent windows with CLR values higher than 5000 $\left(P_{C L R}<0.003\right)$. The top region encompassed 5 genes (Fig. 4a \& e). The variant density in the top region was low and SNP allele frequency was skewed which is typical for the presence of a hard sweep (Fig. 4c). The top iHS candidate region was located on chromosome 11 between 68.4 and $69.2 \mathrm{Mb}\left(P_{i H S}=3.2 \times 10^{-5}\right)$ encompassing 7 genes (Fig. 4b \& f). The allele frequencies of the SNPs within the top iHS region are approaching fixation indicating ongoing selection possibly due to hitchhiking with the neighboring hard sweep (Fig. 4d).

Another striking CLR signal $\left(P_{C L R}=0.0012\right)$ was detected on chromosome 6 between 38.5 and $39.4 \mathrm{Mb}$. This genomic region encompasses the DCAF16, FAM184B, LAP3, LCORL, MED28 and NCAPG genes, and the window with the highest CLR value overlapped the NCAPG gene (Fig. 5a \& c). This signature of selection coincides with a QTL that is associated with stature, feed efficiency and fetal growth [24-26]. Most SNPs detected within this region were fixed for the alternate allele in the $\mathrm{OB}$ key ancestor animals of our study
(Fig. 5b). All 49 sequenced OB cattle were homozygous for the Chr6:38777311 G-allele which results in a likely deleterious (SIFT score 0.01) amino acid substitution (p.I442M) in the NCAPG gene that is associated with increased pre- and postnatal growth and calving difficulties [24].

\section{GO enrichment analysis}

Genes within candidate signatures of selection from CLR and iHS analyses were enriched (after correcting for multiple testing) in the panther pathway (P00011) related to "Blood coagulation". Genes within candidate signatures of selection from CLR tests were also enriched in the pathway "P53 pathway feedback loops 1" (Additional file 10). Although we did not find any enrichment of GO-slim biological processes after correcting for multiple testing, 21 GO-slim biological processes including cellular catabolic processes, oxygen transport and different splicing pathways were nominally enriched for genes within CLR candidate signatures of selection and 14 GO-slim biological processes including nervous system, sensory perception (olfactory receptors) and multicellular processes were nominally enriched for genes within iHS candidate signatures of selection (Additional file 10). 


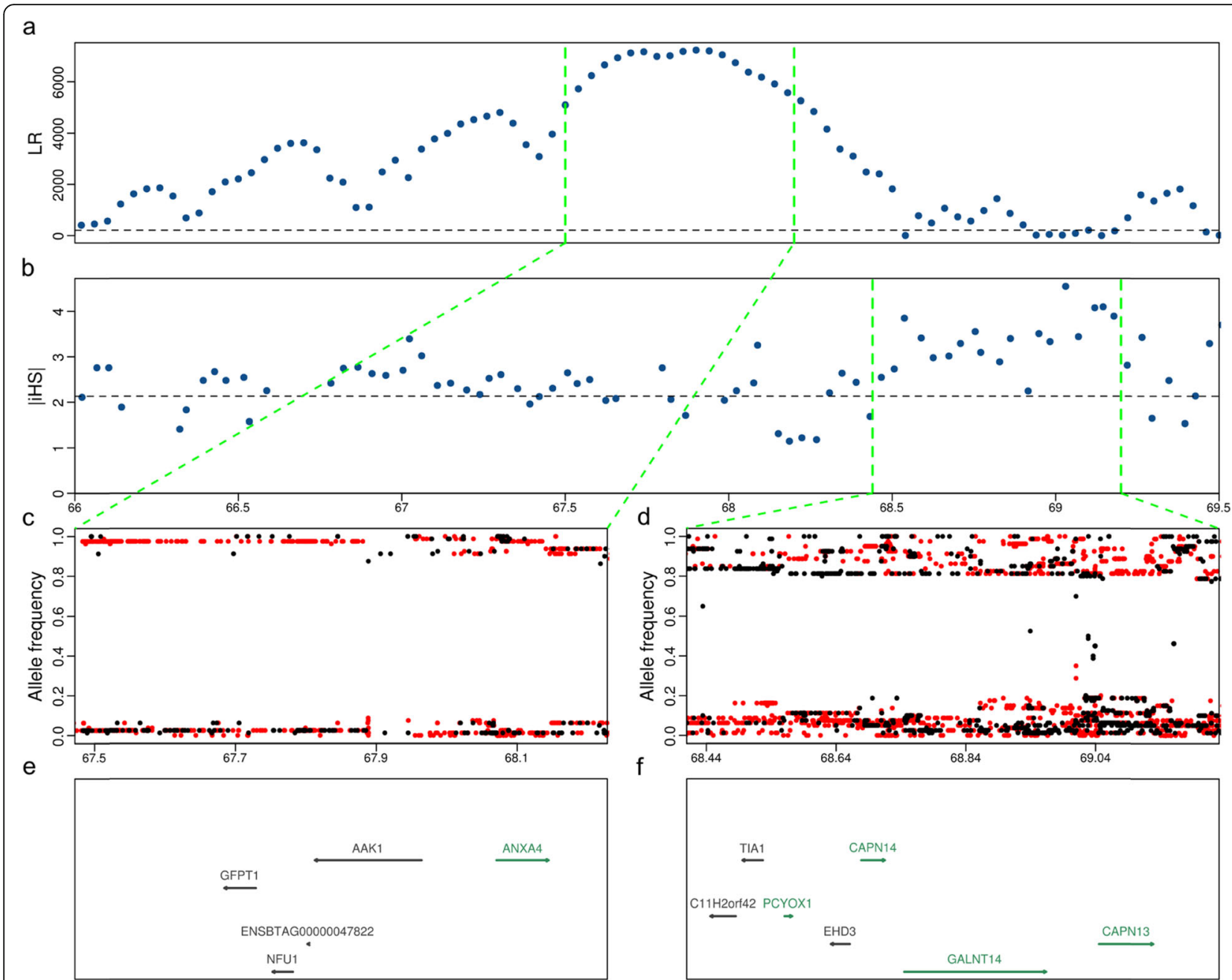

Fig. 4 Detailed view of a top candidate selection region on chromosome 11 in OB that was detected using CLR tests (a) and iHS (b). Each point represents a non-overlapping window of $40 \mathrm{~kb}$. The dotted horizontal lines indicate the cutoff values (top 0.5\%) for CLR (210) and iHS (2.13) statistics. The allele frequencies of the derived (red) or alternate alleles (black) (c and $\mathbf{d}$ ) and genes (e and $\mathbf{f}$ ) in the peak region (67.5-68.2 Mb) of the top CLR (66-68.5 Mb) and iHS (68.4-69.2 Mb) regions. Green and black colour indicates genes on the forward and reverse strand of DNA, respectively

\section{QTL enrichment analysis}

We investigated if candidate selection regions overlapped with trait-associated genomic regions using QTL information curated at the Animal QTL Database (Animal QTLdb). We found that 74.7 and $83.9 \%$ of CLR and iHS candidate signatures of selection, respectively, were overlapping at least one QTL (Additional file 11). We tested for enrichment of these signatures of selection in QTL for six trait classes: exterior, health, milk, meat, production, and reproduction using permutation. It turned out that QTL associated with meat quality $\left(P_{C L R}=0.0004, P_{i H S}=0.0003\right)$ and production traits $\left(P_{C L R}=0.0027, P_{i H S}=0.0039\right)$ were significantly enriched in both CLR and iHS candidate signatures of selection. We did not detect any enrichment of QTL associated with milk, reproduction, health, and exterior traits neither in CLR nor in iHS candidate signatures of selection.

\section{Discussion}

We discovered 107,291 variants in coding sequences of 49 sequenced $\mathrm{OB}$ cattle. In agreement with previous studies in cattle [14, 27], missense deleterious and high impact variants occurred predominantly at low allele frequency likely indicating that variants which disrupt physiological protein functions are removed from the population through purifying selection [28]. However, deleterious variants may reach high frequency in livestock populations due to the frequent use of individual carrier animals in artificial insemination [29], hitchhiking with favorable alleles under artificial selection [30, 31], or demography effects such as population bottlenecks [32]. Because we predicted functional consequences of missense variants using computational inference, they have to be treated with caution in the absence of experimental validation [33]. High impact variants that 


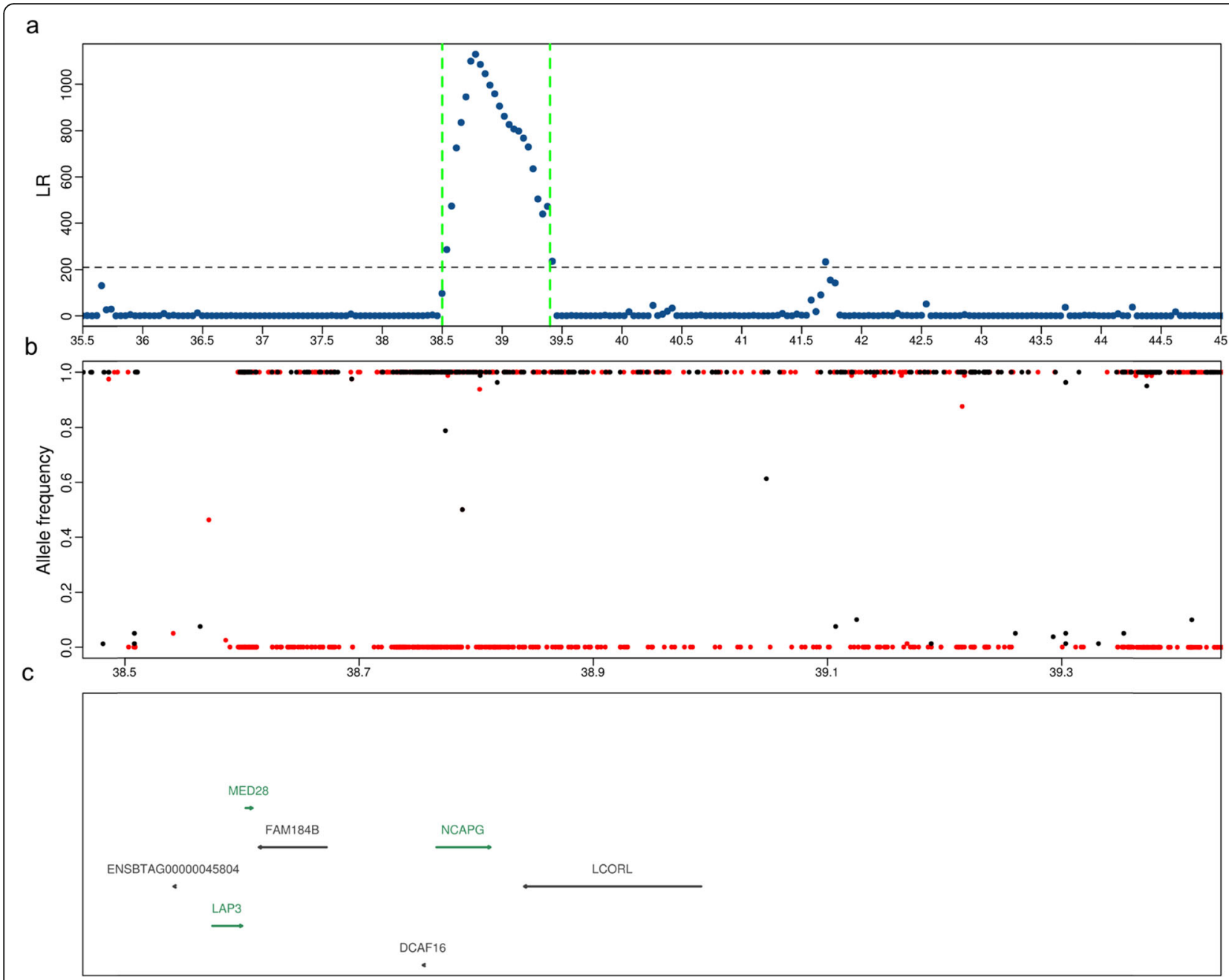

Fig. 5 Top CLR candidate region on chromosome 6 (a). Each point represents a non-overlapping window of $40 \mathrm{~kb}$. The frequencies of the derived (red) or alternate alleles (black) (b) and genes (c) annotated between 38.5 and $39.4 \mathrm{Mb}$. Green and black colour indicates genes on the forward and reverse strand of DNA, respectively

segregated among the 49 sequenced OB key ancestors were also listed as Mendelian trait-associated variants in the OMIA database. For instance, we detected frameshift and missense variants in MOCOS and SLC45A2 that are associated with recessive xanthinuria [19] and oculocutaneous albinism [20], respectively. To the best of our knowledge, calves neither with xanthinuria nor oculocutaneous albinism have been reported in the Swiss OB cattle population. The absence of affected calves is likely due to the low frequencies of the deleterious alleles and avoidance of matings between closely related heterozygous carriers. Among 49 sequenced cattle, we detected only two bulls that carried the disease-associated MOCOS and SLC45A2 alleles in the heterozygous state. However, the frequent use of individual carrier bulls in artificial insemination might result in an accumulation of diseased animals within short time even when the frequency of the deleterious allele is low in the population
[34]. Because the deleterious alleles were detected in sequenced key ancestor animals that were born decades ago, we cannot preclude that they were lost due to genetic drift or during the recent population bottleneck in OB (Additional file 1). A frameshift variant in SLC2A2 (NM_001103222:c.771_778delTTGAAAAGinsCATC, rs379675307, OMIA 000366-9913) causes a recessive disorder in cattle that resembles human Fanconi-Bickel syndrome [35-37]. Recently, the disease-causing allele was detected in the homozygous state in an OB calf with retarded growth due to liver and kidney disease [38]. We did not detect the disease-associated allele in our study. This may be because it is located on a rare haplotype that does not segregate in the 49 sequenced cattle. Most of the sequenced animals of the present study were selected for sequencing using the key ancestor approach, as their genes contributed significantly to the current population [17, 39]. More sophisticated methods to 
select animals for sequencing might prioritize rare haplotypes, thus increasing the likelihood to detect rarer alleles when the sequencing budget is constrained [4042].

\section{Genomic diversity and genomic inbreeding}

Original Braunvieh is a local cattle breed with approximately 10,000 cows registered in the breeding population and 4500 calves entering the herd book every year (Additional file 1). In spite of the small population size, the nucleotide diversity $\left(\pi=1.6 \times 10^{-3}\right)$ is higher in $\mathrm{OB}$ than many taurine cattle breeds with considerably more breeding animals including Holstein, Jersey and Fleckvieh $\left(\sim 1.2-1.4 \times 10^{-3}\right)[43,44]$. However, nucleotide diversity is lower in $\mathrm{OB}$ than African indigenous cattle breeds $\left(2.0-4.0 \times 10^{-3}\right)$, New Danish Red $\left(1.7 \times 10^{-3}\right)$ and Yakutian cattle breeds $\left(1.7 \times 10^{-3}\right)$ [44-46]. The average $\mathrm{F}_{\mathrm{ROH}}$ estimated from WGS data was 0.14 in OB. This is lower than WGS-based $\mathrm{F}_{\mathrm{ROH}}$ in Holstein (0.18), Jersey (0.24), Old Danish Red (0.23) and Belgian Blue (0.3) cattle $[47,48]$. However, the genomic inbreeding is slightly higher in OB than New Red Danish cattle (0.11), an admixed breed that contains genes from old Danish and other red breeds [47]. The relatively high genomic diversity of $\mathrm{OB}$ cattle is assumed to be the result of many different sires contributing to the gene pool due to frequent use of natural mating [10]. Our WGS based estimate of $\mathrm{F}_{\mathrm{ROH}}(0.14)$ is substantially higher than previous estimates obtained using $50 \mathrm{~K}$ SNP microarray data $\left(\mathrm{F}_{\mathrm{ROH}}=0.029,[10]\right)$ for the same population. Genotype data obtained using SNP microarrays with medium density (e.g., BovineSNP50) facilitate to detect long ROH $(>1 \mathrm{Mb})$. However, due to low SNP density $(\sim 1 \mathrm{SNP}$ per $50 \mathrm{~kb}$ ) detecting short $\mathrm{ROH}$ is not possible using microarray-derived genotype data. In our data, short and medium-sized $\mathrm{ROH}$ accounted for $80.48 \%$ of total inbreeding. Most short and medium-sized $\mathrm{ROH}$ are not reliably detectable with the SNP microarrays that were used to quantify $\mathrm{F}_{\mathrm{ROH}}$ in Signer-Hasler et al. [10], resulting in an underestimation of genomic inbreeding. Our estimate of the genomic inbreeding using WGS variants also includes short and medium-sized $\mathrm{ROH}$ that were previously missed using SNP array data, thus representing a realistic estimate of total genomic inbreeding in OB cattle.

Apart from genomic inbreeding, $\mathrm{ROH}$ also provide information about population and individual demography [49-51]. Our findings show that medium-sized $\mathrm{ROH}$ that reflect historical inbreeding contribute most to the genomic inbreeding of the current $\mathrm{OB}$ population. The minor contribution of long $\mathrm{ROH}$ to the genomic inbreeding indicates that recent inbreeding is relatively low in OB possibly due to use of many sires in natural matings as suggested by Hagger [9] and Signer-Hasler et al. [10]. Our results based on $\mathrm{ROH}$ inferred from WGS variants corroborate that genomic inbreeding is lower in OB than most mainstream breeds [10]. However, comparing the number and size distribution of $\mathrm{ROH}$ across studies is subject to bias because misplaced genomic segments might break $\mathrm{ROH}$ into multiple small- and medium-sized $\mathrm{ROHs}$ and different $\mathrm{ROH}$ detection approaches yield results that are not readily comparable [49, 52-55]. Genomic inbreeding is increasing in the $\mathrm{OB}$ population in recent years mainly due to an increase in occurrence of long $\mathrm{ROH}$. The recent population bottleneck in the $\mathrm{OB}$ population (Additional file 1) might promote matings between closely related animals that caused inbreeding to increase in recent generations. In this regard, genome-based mating strategies seem to be warranted to achieve sufficient genetic gain while maintaining genetic diversity and avoiding matings between carriers of disease-associated alleles $[56,57]$.

\section{Signatures of selection}

With WGS data, we were able to identify more signatures of selection compared to SNP array data [10, 58], even though we used only 9 million SNP for which we could readily assign ancestral and derived alleles [59]. Using two complementary approaches, we found several new and known candidate regions that seem to be targets of recent or ongoing selection in OB. Many signatures of selection were located in non-coding regions corroborating that selection frequently acts on regulatory sites [16]. However, it is possible that an improved annotation of the bovine genome might place these regions in yet to be annotated coding regions. We applied methods to detect signatures of selection that depend on frequency changes of alleles (CLR) and haplotypes (iHS). The detected signatures of selection may be confounded by other evolutionary forces including genetic drift and background selection [60-62].

We detected candidate selection regions in $\mathrm{OB}$ cattle that harbor genes associated with stature or milk production (NCAPG, LCORL, LAP3), feed efficiency or lipid metabolism (R3HDM1, $A O X 1)$, and unknown functions (SLC25A33, TMEM201) that were previously reported to be targets of selection in taurine and indicine cattle breeds [16, 63-65]. The presence of signatures of selection that are common in several breeds indicates that selection at these regions has happened either before the breeds diverged or independently after the formation of breeds $[16,65]$. A number of genes that are targets of selection in various cattle breeds are associated with either coat colour $(M C 1 R, K I T)$, milk production (DGAT1, $A B C G 2, G H R$ ) or stature (PLAG1) [44, 65-67]. These genes were not detected within the top 0.5\% CLR and iHS windows in $\mathrm{OB}$ cattle possibly either due to absence 
of trait-associated genomic variation in our data or because they are not under selection in OB cattle. While some cattle breeds including Holstein and Fleckvieh are selected for particular coat colour patterns [66, 68], animals with variation in coat colour are rarely observed in the OB cattle breed [69]. Moreover, due to the use of OB cattle for both milk and beef production under extensive conditions, the milk production-associated variants that are under strong artificial selection in many dairy breeds seem to be less important in OB cattle [64].

Some of the genes (PLAG1, DGAT1, ABCG2, GHR) that have been reported to be targets of selection in specialized breeds contain well-known variants that contribute to the genetic variation of economically important traits. We investigated if these variants segregate in our data although they were not detected in our selection signature analysis. A number of variants in high linkage disequilibrium stimulate the expression of PLAG1, thus increasing pre- and postnatal growth in cattle $[25,26$, 70]. Among 14 candidate causal variants for the PLAG1 QTL, six were fixed for the stature-decreasing alleles in our study (Additional file 12). The other candidate causal variants were either fixed for the statureincreasing allele or segregated at low allele frequency. This pattern indicates that a recombinant haplotype might segregate in Swiss OB cattle that could facilitate fine-mapping of this region. Among known mutations affecting milk production traits, a mutation in ABCG2 (p.Y581S, rs43702337 at 38,027,010 bp) [71] did not segregate in our population of Swiss OB cattle which corroborates previous findings in Brown Swiss cattle [72]. A variant (BTA14, g.1802265_1802266GC > AA, p.A232K) of the DGAT1 gene is associated with milk production traits in cattle [73, 74]. The milk fat-enhancing and milk yield-lowering lysine-allele segregates in $\mathrm{OB}$ cattle at low frequency (0.03). A missense variant (BTA20, g.31909478A > T, p.Y279F) in the GHR gene is associated with milk protein percentage [75]. The protein fat percentage-lowering $\mathrm{T}$-allele segregates at low frequency (0.06) in OB cattle.

We observed a striking signature of selection on chromosome 11 that has previously been detected in the Swiss Fleckvieh, Simmental, Eringer and Evolèner breeds using microarray-called genotypes $[10,58]$. Our results in $\mathrm{OB}$ cattle indicate that this region harbors a rapid sweep which seems to act on alleles with selection advantage [22]. While large sweeps are easy to detect using dense sequencing data, pinpointing causal alleles underpinning such regions remains challenging. Most of the variants in such regions are either fixed or segregate at very low frequency [16] which we also observed for the signature of selection on chromosome 11. In our study, the signature of selection on chromosome 11 encompassed millions of nucleotides (between 66 and $72 \mathrm{Mb}$ ) and many genes, rendering the identification of underpinning genes and variants a difficult task. The windows with the highest CLR and $|\mathrm{iHS}|$ values did not encompass $P R O K R 1$, which was previously suggested to be the target of selection at this region due to its association with fertility [10, 58]. However, closer inspection of the sequence variants detected in our study revealed that a stop-gained variant in PROKR1 (g.66998234C > A, rs476744845, p.Y293*) segregates at high frequency in the 49 sequenced OB key ancestors. Yet, it remains to be elucidated, if the presence of a high-impact variant in immediate proximity to a massive selective sweep is causal or just due to hitchhiking. The window with the largest $|\mathrm{iHS}|$ value on chromosome 11 was right next to the CAPN13 gene which is associated with meat tenderness and was also suggested as a potential target of selection by Signer-Hasler et al. [10].

Genes within the top $0.5 \%$ CLR and iHS windows were enriched in pathways related to reactive oxygen species, metabolic process, blood coagulation and nervous system, indicating that the identified regions under selection might harbor genomic variants that confer adaptive advantage to harsh environments. Moreover, QTL associated with meat quality and production traits including feed efficiency and body weight were enriched in selection signatures possibly indicating that $\mathrm{OB}$ cattle harbor variants that enabled them to adapt to particular feed conditions. Combining results from selection signature and association analyses might reveal phenotypic characteristics associated with genomic regions that showed evidence of past or ongoing selection [66], thus providing additional hints why particular genomic regions are under selection in $\mathrm{OB}$ cattle.

\section{Conclusions}

We provide a comprehensive overview of genomic variation segregating in the Swiss OB cattle population using sequencing data of 49 key ancestor bulls. In spite of the small population size, genetic diversity is higher and genomic inbreeding is lower in $\mathrm{OB}$ than many other mainstream cattle breeds. However, genomic inbreeding is increasing in recent generations mainly due to large $\mathrm{ROH}$ which should be considered in future management of this breed. Finally, this study highlights regions that show evidence of past and ongoing selection in $\mathrm{OB}$ which are enriched for QTL related to meat quality and production traits and pathways related to blood coagulation, cellular metabolic process, and nervous system.

\section{Methods}

\section{Sequence variant genotyping}

We considered genotypes at 17,303,689 biallelic variants $(15,722,811$ SNPs and 1,580,878 Indels) that were discovered and genotyped previously [17] in the autosomes 
of 49 key ancestors of the OB population using a genome graph-based sequence variant genotyping approach [76]. In brief, $49 \mathrm{OB}$ cattle were sequenced at between 6 and 38 -fold genome coverage using either Illumina HiSeq 2500 (30 animals) or Illumina HiSeq 4000 (19 animals) instruments. The sequencing reads were filtered and subsequently aligned to the UMD3.1 assembly of the bovine genome [77] using the mem-algorithm of the Burrows Wheeler Aligner (BWA) software package [78]. Single nucleotide and short insertion and deletion polymorphisms were discovered and genotyped using the Graphtyper software [76]. Following recommended filtration criteria (see Crysnanto et al. [17] for more details), 15,722,811 SNPs and 1,580,878 Indels were retained for subsequent analyses. Beagle [53] phasing and imputation was applied to improve the primary genotype calls from Graphtyper and infer missing genotypes. Unless stated otherwise, imputed genotypes were considered for subsequent analyses, because Beagle imputation considerably improved the primary genotype calls particularly in samples that had been sequenced at low coverage [17].

\section{Variant annotation and evaluation}

Functional consequences of 15,722,811 SNPs and 1,580, 878 Indels were predicted according to the Ensembl (release 91) annotation of the bovine genome assembly UMD3.1 using the Variant Effect Predictor tool (VEP v.91.3) [79] with default parameter settings. The impacts of amino acid substitutions on protein function were predicted using the sorting intolerant from tolerant (SIFT) (version 5.2.2) [80] algorithm that has been implemented in the VEP tool. Variants with SIFT scores less than 0.05 were considered to be likely deleterious to protein function. In order to assess if known Mendelian traitassociated variants segregate among 49 sequenced $O B$ cattle, we downloaded genomic coordinates of 155 traitassociated variants that are curated in the Online Mendelian Inheritance in Animals (OMIA) database [81, 82].

\section{Population genetic analysis}

Nucleotide diversity $(\pi)$ quantifies the average number of nucleotide differences per site between two DNA sequences that originated from the studied population [83]. We estimated $\pi$ of the OB population over the entire autosomal genome using VCFtools v0.1.15 (in windows of $10 \mathrm{~kb}$ ) [55].

\section{Detection of runs of homozygosity}

Runs of homozygosity were identified using a Hidden Markov Model (HMM)-based approach implemented in the BCFtools/RoH software [84, 85]. The recombination rate was assumed to be constant along the genome at $10^{-8}$ per base pair $(1 \mathrm{cM} / \mathrm{Mb})$. For the HMM-based detection of $\mathrm{ROH}$, we considered phred-scaled likelihoods (PL) and allele frequencies of 15,722,811 filtered SNPs before Beagle imputation. Because samples that are sequenced at low coverage are enriched for $\mathrm{ROH}$ [86], we considered only 33 samples with average sequencing coverage greater than 10 -fold for the detection of $\mathrm{ROH}$ (Additional file 13). We only considered $\mathrm{ROH}$ longer than $50 \mathrm{~kb}$ because they were less likely to contain false-positives (Phred-score $>67$ in our data, Additional file 13). Genomic inbreeding $\left(\mathrm{F}_{\mathrm{ROH}}\right)$ was calculated for each animal as $\mathrm{F}_{\mathrm{ROH}}=\Sigma \mathrm{L}_{\mathrm{ROH}} / \mathrm{L}_{\mathrm{GENOME}}$, where $\Sigma \mathrm{L}_{\mathrm{ROH}}$ is the length of all $\mathrm{ROH}$ longer than $50 \mathrm{~kb}$ and $\mathrm{L}_{\mathrm{GENOME}}$ is the length of the genome covered by SNPs [87], which is $2,512,054,768$ bp in our data.

Further, ROH were classified into short $(50-100 \mathrm{~kb})$, medium $(0.1-2 \mathrm{Mb})$ and long $\mathrm{ROH}(>2 \mathrm{Mb})$ reflecting ancient, historical, and recent inbreeding, respectively [88]. The contribution of each $\mathrm{ROH}$ category to $\mathrm{F}_{\mathrm{ROH}}$ was calculated for each animal. Average genomic inbreeding was compared between animals born before and after 1989 using the two samples t-test.

\section{Detection of signatures of selection}

To avoid potential bias arising from extended relationships among the sequenced animals, we did not consider nine sons from sire-son pairs for the detection of signatures of selection. For the remaining 40 cattle, we considered genotypes at 9,051,833 SNPs for which the ancestral allele provided by Rocha et al. [59] was detected in at least two species other than cattle and where it agreed with either the reference or alternate allele in our data. Haplotypes were phased using the Eagle2 software [89] with default parameter settings and assuming a constant recombination rate along the chromosome.

\section{Integrated haplotype score (iHS)}

To identify signatures of ongoing selection, integrated haplotype scores (iHS) were calculated for 8,465,912 variants with minor allele frequency (MAF) greater than 0.01 using the R package rehh v.2 [90]. We obtained iHS that ranged from -6.6 to 6.4 . Subsequently, $|\mathrm{iHS}|$ were averaged for non-overlapping windows of $40 \mathrm{~kb}$ over the whole genome. Windows with either less than 10 SNPs were removed. To test if variants with similar $|\mathrm{iHS}|$ properties were pooled in $40 \mathrm{~kb}$ windows, we followed the approach of Granka et al. [91]. Specifically, we randomly selected the same number of SNPs that were pooled in $40 \mathrm{~kb}$ windows and calculated the mean variance of $|\mathrm{iHS}|$ in the true and permuted $40 \mathrm{~kb}$ windows for each chromosome. This procedure was repeated for 10,000 randomly selected $40 \mathrm{~kb}$ windows. The variance of $|\mathrm{iHS}|$ in the non-overlapping $40 \mathrm{~kb}$ windows (0.24) was significantly $(P<0.01)$ less than in windows of randomly selected SNPs (0.37) indicating that SNPs that 
were grouped in $40 \mathrm{~kb}$ windows had $|\mathrm{iHS}|$ values that were more alike than random SNPs.

\section{Composite likelihood ratio (CLR)}

Composite likelihood ratio (CLR) tests were carried out to identify alleles that are either close to fixation or already reached fixation due to past selection. Following the recommendation of Huber et al. [92], we removed 118,124 SNPs from the data which were fixed for the ancestral alleles because such sites are not informative for CLR tests. Using a pre-computed empirical allele frequency spectrum of 8,933,709 SNPs for which ancestral and derived alleles were assigned (see above), we calculated CLR statistics in non-overlapping $40 \mathrm{~kb}$ windows using SweepFinder2 [93, 94]. A window size of $40 \mathrm{~kb}$ was chosen to allow comparison and alignment between $|\mathrm{iHS}|$ and CLR values.

Empirical $P$ values were calculated for CLR and $|\mathrm{iHS}|$ windows [66] and the top $0.5 \%$ of windows of each statistic were considered as candidate signatures of selection. Adjacent top $0.5 \%$ windows were merged separately for each statistic using BEDTools v2.27.1 [95]. For each merged candidate signature of selection, the lowest $P$ value among the merged windows was retained.

\section{Characterization of signatures of selection}

Genes within candidate signatures of selection were determined based on the Ensembl (release 91) annotation of the UMD3.1 assembly of the bovine genome. Geneset enrichment analysis of genes within candidate signatures of selection was performed using PANTHER v.14.1 [96]. Specifically, we investigated if these genes were enriched in the functional categories of GO-slim Biological Process and PANTHER pathways using $P \leq 0.05$ as significance level.

To determine the overlap between QTL and candidate signatures of selection, we downloaded genomic coordinates for 122,893 QTL from the Animal QTL Database [97, 98]. We classified 85,722 unique QTL that were located on the 29 autosomes into six trait categories: exterior, health, milk, meat and carcass, production and reproduction (Additional file 14). QTL with identical genomic coordinates in associated trait categories were considered as one QTL. We used the intersect module of BEDTools v2.27.1 [95] to identify QTL that overlapped with CLR and |iHS| candidate regions for each of the six trait categories separately. To test if QTL were enriched in candidate signatures of selection, we used a permutation test with 10,000 permutations. In each permutation, we randomly sampled the same number of regions of the same size as the candidate signatures of selection from CLR and |iHS| for each chromosome separately, and overlapped them with QTL of the respective trait categories using BEDTools (see above). The number of QTL that overlapped permuted regions was used as the empirical null distribution to calculate $P$ values. $P$ values less than 0.05 were considered as indicators for a significant enrichment of QTL in candidate signatures of selection.

\section{Supplementary information}

Supplementary information accompanies this paper at https://doi.org/10. 1186/s12864-020-6446-y.

Additional file 1: Original Braunvieh herd book population. Number of female calves entering the OB herd book between 1980 and 2016.

Additional file 2: Allele frequency distribution in different functional annotations. Allele frequency of SNPs with different consequences according to VEP prediction, like high impact, deleterious (missense SNP with SIFT score < 0.05). tolerated (missense SNPs with SIFT score $>0.05$ ) and synonymous SNPS.

Additional file 3: Distribution of length of Indels. a Number of Indels $(\times 1000)$ with size less than 12 bp detected according to the number of affected bases. $\mathbf{b}$ number of Indels detected in coding sequences.

Additional file 4: OMIA variants detected in OB. Six OMIA variants detected in 49 sequenced $O B$ animals with their respective frequency and information.

Additional file 5: $\mathrm{ROH}$ statistics of each animal (high coverage). Number, length, average length and genomic fraction of all $\mathrm{ROH}$ in each animal. Also categorized in short, medium and long $\mathrm{ROH}$ category.

Additional file 6: Genomic inbreeding in $\mathrm{OB}$ cattle stratified by birth year. Genomic inbreeding in two groups of animals born either between 1960 and 1989 or between 1990 and 2012

Additional file 7: Candidate selection signatures detected using CLR. Genomic coordinates, CLR values, $p$ values and encompassed genes for 95 candidate selection signatures.

Additional file 8: Candidate selection signatures detected using iHS. Genomic coordinates, |iHS| values, $p$ values and encompassed genes for 162 candidate selection signatures.

Additional file 9: Overlap between the top CLR and iHS selection signatures. Overlapped regions and genes between CLR and iHS candidate selection regions.

Additional file 10: Summary of Gene Ontology enrichment analysis. PANTHER and GO-Slim pathways enriched using genes encompassed in signatures of selection from CLR and iHS analyses.

Additional file 11: Overlap between QTL and signatures of selection. QTL (from all 6 categories) that overlapped with CLR and iHS selection signatures.

Additional file 12: Frequency of candidate causal variants for a stature QTL on BTA14. Genomic coordinates and allele frequencies of 14 variants nearby bovine PLAG1 that were reported as candidate causal variants for a stature QTL in cattle by Karim et al. [70].

Additional file 13: Runs of homozygosity in $49 \mathrm{OB}$ cattle. a Total genome fraction in $\mathrm{ROH}$ in 49 cattle with high (>10x) and low (<10x) coverage (b) Phred confidence score for $\mathrm{ROH}$ in 33 cattle sequenced at average sequencing depth higher than 10-fold. Red dots indicate mean confidence scores for $\mathrm{ROH}$.

Additional file 14: Bovine QTL information downloaded from the AnimalQTL database. Number of QTL for each trait. Traits are grouped in six trait categories.

\section{Abbreviations}

CLR: Composite likelihood ratio; GO: Gene Ontology; iHS: Integrated haplotype score; OB: Original Braunvieh; OMIA: Online Mendelian Inheritance in Animals; QTL: Quantitative trait loci; ROH: Runs of homozygosity; SNP: Single nucleotide polymorphism; WGS: Whole-genome sequencing 


\section{Acknowledgements}

We thank Braunvieh Schweiz for providing pedigree and genotype data of Original Braunvieh cattle.

\section{Authors' contributions}

Analysis of whole-genome sequencing data: MB NKK DC HP; Conceived and designed the experiments: MB NKK HP; Wrote the paper: MB HP; Read and approved the final version of the manuscript: all authors

\section{Funding}

This study was financially supported by the Federal Office for Agriculture (FOAG), Bern. The funding body was not involved in the design of the study and collection, analysis, and interpretation of data and in writing the manuscript.

\section{Availability of data and materials}

Raw sequencing read data of all animals are available from the European Nucleotide Archive (ENA) (http://www.ebi.ac.uk/ena) under study accession PRJEB28191 (sample accession numbers SAMEA4827645-SAMEA4827674 and SAMEA5059741-SAMEA5059759).

\section{Ethics approval and consent to participate}

Not applicable.

\section{Consent for publication}

Not applicable.

\section{Competing interests}

HP is a member of the editorial board of BMC Genomics. All other authors declare that they have no competing interests.

Received: 14 July 2019 Accepted: 31 December 2019

Published online: 08 January 2020

\section{References}

1. Food and Agriculture Organization. The Second Report on the State of the World's Animal Genetic Resources for Food and Agriculture. Rome: FAO Commission on Genetic Resources for Food and Agriculture Assessments. 2015. www.fao.org/publications.

2. Diversity ECG, Consortium. Marker-assisted conservation of European cattle breeds: an evaluation. Anim Genet. 2006:37:475-81.

3. Medugorac I, Medugorac A, Russ I, Veit-Kensch CE, Taberlet P, Luntz B, et al. Genetic diversity of European cattle breeds highlights the conservation value of traditional unselected breeds with high effective population size. Mol Ecol. 2009;18:3394-410.

4. Boettcher PJ, Hoffmann I, Baumung R, Drucker AG, McManus C, Berg P, et al. Genetic resources and genomics for adaptation of livestock to climate change. Front Genet. 2014;5:461.

5. Biscarini F, Nicolazzi E, Alessandra S, Boettcher P, Gandini G. Challenges and opportunities in genetic improvement of local livestock breeds. Front Genet. 2015;6:33.

6. Jurt C, Häberli I, Rossier R. Transhumance farming in Swiss Mountains: adaptation to a changing environment. Mt Res Dev. 2015;35:57-65.

7. Herzog F, Seidl I. Swiss alpine summer farming: current status and future development under climate change. Rangel J. 2018:40:501-11.

8. Bieber A, Wallenbeck A, Leiber F, Fuerst-Waltl B, Winckler C, Gullstrand P, et al. Production level, fertility, health traits, and longevity in local and commercial dairy breeds under organic production conditions in Austria, Switzerland, Poland, and Sweden. J Dairy Sci. 2019:102:5330-41.

9. Hagger C. Estimates of genetic diversity in the brown cattle population of Switzerland obtained from pedigree information. J Anim Breed Genet. 2005; 122:405-13.

10. Signer-Hasler H, Burren A, Neuditschko M, Frischknecht M, Garrick D, Stricker $C$, et al. Population structure and genomic inbreeding in nine Swiss dairy cattle populations. Genet Sel Evol. 2017;49:83.

11. Matukumalli LK, Lawley CT, Schnabel RD, Taylor JF, Allan MF, Heaton MP et al. Development and characterization of a high density SNP genotyping assay for cattle. PLoS One. 2009:4:e5350.

12. Rowan TN, Hoff JL, Crum TE, Taylor JF, Schnabel RD, Decker JE. A MultiBreed Reference Panel and Additional Rare Variation Maximizes Imputation Accuracy in Cattle. bioRxiv. 2019:517144. https://doi.org/10.1101/517144.
13. Albrechtsen A, Nielsen FC, Nielsen R. Ascertainment biases in SNP chips affect measures of population divergence. Mol Biol Evol. 2010;27:2534-47.

14. Daetwyler HD, Capitan A, Pausch H, Stothard P, van Binsbergen R, Brøndum RF, et al. Whole-genome sequencing of 234 bulls facilitates mapping of monogenic and complex traits in cattle. Nat Genet. 2014;46:858-65.

15. Günther $T$, Nettelblad $C$. The presence and impact of reference bias on population genomic studies of prehistoric human populations. PLOS Genet. 2019;15:e1008302

16. Boitard S, Boussaha M, Capitan A, Rocha D, Servin B. Uncovering adaptation from sequence data: lessons from genome resequencing of four cattle breeds. Genetics. 2016;203:433-50.

17. Crysnanto D, Wurmser $C$, Pausch $\mathrm{H}$. Accurate sequence variant genotyping in cattle using variation-aware genome graphs. Genet Sel Evol. 2019;51:21.

18. Das A, Panitz F, Gregersen VR, Bendixen C, Holm LE. Deep sequencing of Danish Holstein dairy cattle for variant detection and insight into potential loss-offunction variants in protein coding genes. BMC Genomics. 2015;16:1043.

19. Murgiano L, Jagannathan V, Piffer C, Diez-Prieto I, Bolcato M, Gentile A, et al. A frameshift mutation in MOCOS is associated with familial renal syndrome (xanthinuria) in Tyrolean Grey cattle. BMC Vet Res. 2016;12:276.

20. Rothammer S, Kunz E, Seichter D, Krebs S, Wassertheurer M, Fries R, et al. Detection of two non-synonymous SNPs in SLC45A2 on BTA20 as candidate causal mutations for oculocutaneous albinism in Braunvieh cattle. Genet Sel Evol. 2017;49:73.

21. Nielsen R, Williamson S, Kim Y, Hubisz MJ, Clark AG, Bustamante C. Genomic scans for selective sweeps using SNP data. Genome Res. 2005;15:1566-75.

22. Sabeti PC, Schaffner SF, Fry B, Lohmueller J, Varilly P, Shamovsky O, et al. Positive natural selection in the human lineage. Science. 2006;312:1614-20.

23. Voight BF, Kudaravalli S, Wen X, Pritchard JK. A map of recent positive selection in the human genome. PLoS Biol. 2006;4:e72

24. Eberlein A, Takasuga A, Setoguchi K, Pfuhl R, Flisikowski K, Fries R, et al. Dissection of genetic factors modulating fetal growth in cattle indicates a substantial role of the non-SMC condensin I complex, subunit G (NCAPG) gene. Genetics. 2009;183:951-64.

25. Pausch $H$, Flisikowski K, Jung S, Emmerling R, Edel C, Götz KU, et al. Genome-wide association study identifies two major loci affecting calving ease and growth-related traits in cattle. Genetics. 2011;187:289-97.

26. Bouwman AC, Daetwyler HD, Chamberlain AJ, Ponce CH, Sargolzaei M, Schenkel FS, et al. Meta-analysis of genome-wide association studies for cattle stature identifies common genes that regulate body size in mammals. Nat Genet. 2018;50:362-7.

27. Jansen S, Aigner B, Pausch H, Wysocki M, Eck S, Benet-Pagès A, et al. Assessment of the genomic variation in a cattle population by resequencing of key animals at low to medium coverage. BMC Genomics. 2013;14:446

28. Miosge LA, Field MA, Sontani Y, Cho V, Johnson S, Palkova A, et al. Comparison of predicted and actual consequences of missense mutations. Proc Natl Acad Sci U S A. 2015:112:E5189-98.

29. Pausch H, Kölle S, Wurmser C, Schwarzenbacher H, Emmerling R, Jansen S, et al. A nonsense mutation in TMEM95 encoding a nondescript Transmembrane protein causes idiopathic male subfertility in cattle. PLoS Genet. 2014:10:e1004044

30. Kadri NK, Sahana G, Charlier C, Iso-Touru T, Guldbrandtsen B, Karim L, et al. A 660-kb deletion with antagonistic effects on fertility and Milk production segregates at high frequency in Nordic red cattle: additional evidence for the common occurrence of balancing selection in livestock. PLoS Genet. 2014;10:e1004049.

31. Pausch $\mathrm{H}$, Ammermüller $\mathrm{S}$, Wurmser $\mathrm{C}$, Hamann $\mathrm{H}$, Tetens J, Drögemüller $\mathrm{C}$, et al. A nonsense mutation in the COL7A1 gene causes epidermolysis bullosa in Vorderwald cattle. BMC Genet. 2016;17:149.

32. Bosse M, Megens HJ, Derks MFL, de Cara ÁMR, Groenen MAM. Deleterious alleles in the context of domestication, inbreeding, and selection. Evol Appl. 2019:12:6-17.

33. Dong C, Wei $P$, Jian X, Gibbs R, Boerwinkle E, Wang K, et al. Comparison and integration of deleteriousness prediction methods for nonsynonymous SNVs in whole exome sequencing studies. Hum Mol Genet. 2015;24:2125-37.

34. Schwarzenbacher $H$, Wurmser C, Flisikowski $K$, Misurova $L$, Jung $S$, Langenmayer MC, et al. A frameshift mutation in GON4L is associated with proportionate dwarfism in Fleckvieh cattle. Genet Sel Evol. 2016:48:25.

35. Santer R, Schneppenheim R, Dombrowski A, Gotze H, Steinmann B. Mutations in GLUT2, the gene for the liver-type glucose transporter, in patients with Fanconi-Bickel syndrome. Nat Genet. 1997;17:324-6. 
36. Pausch $\mathrm{H}$, Schwarzenbacher $\mathrm{H}$, Burgstaller J, Flisikowski K, Wurmser C, Jansen $\mathrm{S}$, et al. Homozygous haplotype deficiency reveals deleterious mutations compromising reproductive and rearing success in cattle. BMC Genomics. 2015;16:312.

37. Burgstaller J, Url A, Pausch H, Schwarzenbacher H, Egerbacher M, Wittek T. Clinical and biochemical signs in Fleckvieh cattle with genetically confirmed Fanconi-Bickel syndrome (cattle homozygous for Fleckvieh haplotype 2). Berl Munch Tierarztl Wochenschr. 2016:129:132-7.

38. Joller S, Stettler M, Locher I, Dettwiler M, Seefried F, Meylan M, et al. Fanconi-Bickel-Syndrom : eine bislang unerkannte Erbkrankheit beim Braunvieh. Schweizer Archiv Tierheilkunde. 2018;160:179-84.

39. Goddard ME, Hayes BJ. Genomic selection based on dense genotypes inferred from sparse genotypes. Proc Assoc Advmt Anim Breed Gen. 2009; 18:26-9.

40. Gusev A, Shah MJ, Kenny EE, Ramachandran A, Lowe JK, Salit J, et al. Lowpass genome-wide sequencing and variant inference using identity-bydescent in an isolated human population. Genetics. 2012;190:679-89.

41. Bickhart DM, Hutchison JL, Null DJ, VanRaden PM, Cole JB. Reducing animal sequencing redundancy by preferentially selecting animals with lowfrequency haplotypes. J Dairy Sci. 2016;99:5526-34.

42. Ros-Freixedes R, Gonen S, Gorjanc G, Hickey JM. A method for allocating low-coverage sequencing resources by targeting haplotypes rather than individuals. Genet Sel Evol. 2017:49:78.

43. Charlier C, Li W, Harland C, Littlejohn M, Coppieters W, Creagh F, et al. NGSbased reverse genetic screen for common embryonic lethal mutations compromising fertility in livestock. Genome Res. 2016;26:1333-41.

44. Mei C, Wang H, Liao Q, Wang L, Cheng G, Wang H, et al. Genetic architecture and selection of Chinese cattle revealed by whole genome resequencing. Mol Biol Evol. 2018;35:688-99.

45. Kim J, Hanotte O, Mwai OA, Dessie T, Salim B, Diallo B, et al. The genome landscape of indigenous African cattle. Genome Biol. 2017;18:34.

46. Weldenegodguad M, Popov R, Pokharel K, Ammosov I, Ming Y, Ivanova Z, et al. Whole-genome sequencing of three native cattle breeds originating from the northernmost cattle farming regions. Front Genet. 2019;9:728.

47. Zhang Q, Guldbrandtsen B, Bosse M, Lund MS, Sahana G. Runs of homozygosity and distribution of functional variants in the cattle genome BMC Genomics. 2015;16:542.

48. Solé M, Gori AS, Faux P, Bertrand A, Farnir F, Gautier M, et al. Age-based partitioning of individual genomic inbreeding levels in Belgian blue cattle. Genet Sel Evol. 2017:49:92

49. Bosse M, Megens $H$, Madsen $O$, Paudel Y, Frantz LAF, Schook LB, et al. Regions of Homozygosity in the porcine genome : consequence of demography and the recombination landscape. PLoS Genet. 2012:8:e1003100.

50. Purfield DC, Berry DP, McParland S, Bradley DG. Runs of homozygosity and population history in cattle. BMC Genet. 2012;13:70.

51. Ceballos FC, Joshi PK, Clark DW, Ramsay M, Wilson JF. Runs of homozygosity: windows into population history and trait architecture. Nat Rev Genet. 2018;19:220-34

52. Purcell S, Neale B, Todd-Brown K, Thomas L, Ferreira MAR, Bender D, et al. PLINK: a tool set for whole-genome association and population-based linkage analyses. Am J Hum Genet. 2007;81:559-75.

53. Browning SR, Browning BL. Rapid and accurate haplotype phasing and missing-data inference for whole-genome association studies by use of localized haplotype clustering. Am J Hum Genet. 2007;81:1084-97.

54. Bertrand AR, Kadri NK, Flori L, Gautier M, Druet T. RZooRoH: an R package to characterize individual genomic autozygosity and identify homozygous-bydescent segments. Methods Ecol Evol. 2019;10:860-6.

55. Danecek P, Auton A, Abecasis G, Albers CA, Banks E, DePristo MA, et al. The variant call format and VCFtools. Bioinformatics. 2011;27:2156-8.

56. Wellmann R. Optimum contribution selection for animal breeding and conservation: the R package optiSel. BMC Bioinformatics. 2019;20:25.

57. Cole JB. A simple strategy for managing many recessive disorders in a dairy cattle breeding program. Genet Sel Evol. 2015;47:94.

58. Rothammer S, Seichter D, Förster M, Medugorac I. A genome-wide scan for signatures of differential artificial selection in ten cattle breeds. BMC Genomics. 2013;14:908.

59. Rocha D, Billerey C, Samson F, Boichard D, Boussaha M. Identification of the putative ancestral allele of bovine single-nucleotide polymorphisms. J Anim Breed Genet. 2014;131:483-6.

60. Biswas S, Akey JM. Genomic insights into positive selection. Trends Genet. 2006:22:437-46
61. Akey JM. Constructing genomic maps of positive selection in humans: where do we go from here? Genome Res. 2009;19:711-22.

62. Charlesworth B. The role of background selection in shaping patterns of molecular evolution and variation: evidence from variability on the Drosophila X chromosome. Genetics. 2012;191:233-46.

63. Gutiérrez-Gil B, Arranz JJ, Wiener P. An interpretive review of selective sweep studies in Bos taurus cattle populations: identification of unique and shared selection signals across breeds. Front Genet. 2015;6:167.

64. Zhao F, McParland S, Kearney F, Du L, Berry DP. Detection of selection signatures in dairy and beef cattle using high-density genomic information. Genet Sel Evol. 2015:47:49.

65. Xu L, Bickhart DM, Cole JB, Schroeder SG, Song J, Van Tassell CP, et al. Genomic signatures reveal new evidences for selection of important traits in domestic cattle. Mol Biol Evol. 2015;32:711-25.

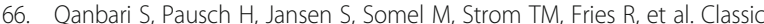
selective sweeps revealed by massive sequencing in cattle. PLoS Genet. 2014;10:e1004148.

67. Randhawa IAS, Khatkar MS, Thomson PC, Raadsma HW. Composite Selection Signals for Complex Traits Exemplified Through Bovine Stature Using Multibreed Cohorts of European and African Bos taurus. G3 (Bethesda, Md). 2015:5:1391-401.

68. Joerg H, Fries HR, Meijerink E, Stranzinger GF. Red coat color in Holstein cattle is associated with a deletion in the MSHR gene. Mamm Genome. 1996;7:317-8.

69. Durkin K, Coppieters W, Drögüller C, Ahariz N, Cambisano N, Druet T, et al. Serial translocation by means of circular intermediates underlies colour sidedness in cattle. Nature. 2012;482:81-4.

70. Karim L, Takeda H, Lin L, Druet T, Arias JAC, Baurain D, et al. Variants modulating the expression of a chromosome domain encompassing PLAG1 influence bovine stature. Nat Genet. 2011:43:405-15.

71. Cohen-Zinder M, Seroussi E, Larkin DM, Loor JJ. Everts-Van Der wind a, lee $\mathrm{JH}$, et al. identification of a missense mutation in the bovine ABCG2 gene with a major effect on the QTL on chromosome 6 affecting milk yield and composition in Holstein cattle. Genome Res. 2005:15:936-44.

72. Pausch H, Emmerling R, Gredler-Grandl B, Fries R, Daetwyler HD, Goddard ME. Meta-analysis of sequence-based association studies across three cattle breeds reveals 25 QTL for fat and protein percentages in milk at nucleotide resolution. BMC Genomics. 2017;18:853.

73. Grisart B, Coppieters W, Farnir F, Karim L, Ford C, Berzi P, et al. Positional candidate cloning of a QTL in dairy cattle: identification of a missense mutation in the bovine DGAT1 gene with major effect on milk yield and composition. Genome Res. 2002;12:222-31.

74. Winter A, Kramer W, Werner FAO, Kollers S, Kata S, Durstewitz G, et al. Association of a lysine-232/alanine polymorphism in a bovine gene encoding acyl-CoA:diacylglycerol acyltransferase (DGAT1) with variation at a quantitative trait locus for milk fat content. Proc Natl Acad Sci U S A. 2002; 99:9300-5.

75. Blott S, Kim JJ, Moisio S, Schmidt-Küntzel A, Cornet A, Berzi P. Molecular dissection of a quantitative trait locus: a phenylalanine-to-tyrosine substitution in the transmembrane domain of the bovine growth hormone receptor is associated with a major effect on milk yield and composition. Genetics. 2003;163:253-66.

76. Eggertsson HP, Jonsson $\mathrm{H}$, Kristmundsdottir S, Hjartarson E, Kehr B, Masson $\mathrm{G}$, et al. Graphtyper enables population-scale genotyping using pangenome graphs. Nat Genet. 2017;49:1654-60.

77. Zimin AV, Delcher AL, Florea L, Kelley DR, Schatz MC, Puiu D. A wholegenome assembly of the domestic cow. Genome Biol. 2009;10:R42.

78. Li H. Aligning sequence reads, clone sequences and assembly contigs with BWA-MEM. arXiv:13033997v2. 2013;00:1-3 http://arxiv.org/abs/1303.3997.

79. McLaren W, Gil L, Hunt SE, Riat HS, Ritchie GRS, Thormann A, et al. The Ensembl variant effect predictor. Genome Biol. 2016;17:122.

80. Kumar P, Henikoff S, Ng PC. Predicting the effects of coding nonsynonymous variants on protein function using the SIFT algorithm. Nat Protoc. 2009:4:1073-82.

81. Online Mendelian Inheritance in Animals database (OMIA). https://omia.org/ home. Accessed 10 Oct 2018.

82. Nicholas FW, Hobbs M. Mutation discovery for Mendelian traits in nonlaboratory animals: a review of achievements up to 2012. Anim Genet. 2014 45:157-70.

83. Nei M, Li WH. Mathematical model for studying genetic variation in terms of restriction endonucleases. Proc Natl Acad Sci U S A. 1979;76:5269-73. 
84. Narasimhan V, Danecek P, Scally A, Xue Y, Tyler-Smith C, Durbin R. BCFtools/ RoH: a hidden Markov model approach for detecting autozygosity from next-generation sequencing data. Bioinformatics. 2016;32:1749-51.

85. Xue Y, Prado-Martinez J, Sudmant PH, Narasimhan V, Ayub Q, Szpak M, et al. Mountain gorilla genomes reveal the impact of long-term population decline and inbreeding. Science. 2015;348:242-5.

86. van der Valk T, Díez-del-Molino D, Marques-Bonet T, Guschanski K, Dalén L. Historical genomes reveal the genomic consequences of recent population decline in eastern gorillas. Curr Biol. 2019;29:165-70.

87. McQuillan R, Leutenegger AL, Abdel-Rahman R, Franklin CS, Pericic M, Barac-Lauc $L$, et al. Runs of Homozygosity in European populations. Am J Hum Genet. 2008;83:359-72.

88. Kirin M, McQuillan R, Franklin CS, Campbell H, McKeigue PM, Wilson JF. Genomic runs of homozygosity record population history and consanguinity. PLoS One. 2010:5:e13996.

89. Loh PR, Danecek P, Palamara PF, Fuchsberger C, Reshef YA, Finucane HK, et al. Reference-based phasing using the haplotype reference consortium panel. Nat Genet. 2016;48:1443-8.

90. Gautier M, Klassmann A, Vitalis R. Rehh 2.0: a reimplementation of the $R$ package rehh to detect positive selection from haplotype structure. Mol Ecol Resour. 2017;17:78-90.

91. Granka JM, Henn BM, Gignoux CR, Kidd JM, Bustamante CD, Feldman MW. Limited evidence for classic selective sweeps in African populations. Genetics. 2012;192:1049-64.

92. Huber CD, DeGiorgio M, Hellmann I, Nielsen R. Detecting recent selective sweeps while controlling for mutation rate and background selection. Mol Ecol. 2015;25:142-56.

93. Nielsen R. Molecular signatures of natural selection. Annu Rev Genet. 2005: 39:197-218.

94. Degiorgio M, Huber CD, Hubisz MJ, Hellmann I, Nielsen R. SweepFinder2: increased sensitivity, robustness and flexibility. Bioinformatics. 2016;32:18957.

95. Quinlan AR, Hall IM. BEDTools: a flexible suite of utilities for comparing genomic features. Bioinformatics. 2010;26:841-2.

96. Mi H, Muruganujan A, Ebert D, Huang X, Thomas PD. PANTHER version 14 more genomes, a new PANTHER GO-slim and improvements in enrichment analysis tools. Nucleic Acids Res. 2019;47:D419-26.

97. Hu ZL, Park CA, Reecy JM. Building a livestock genetic and genomic information knowledgebase through integrative developments of animal QTLdb and CorrDB. Nucleic Acids Res. 2019;47:D701-10.

98. The Animal Quantitative Trait Loci (QTL) Database. https://www. animalgenome.org/QTLdb/cattle. Accessed 8 Mar 2019.

\section{Publisher's Note}

Springer Nature remains neutral with regard to jurisdictional claims in published maps and institutional affiliations.

Ready to submit your research? Choose BMC and benefit from:

- fast, convenient online submission

- thorough peer review by experienced researchers in your field

- rapid publication on acceptance

- support for research data, including large and complex data types

- gold Open Access which fosters wider collaboration and increased citations

- maximum visibility for your research: over $100 \mathrm{M}$ website views per year

At $\mathrm{BMC}$, research is always in progress.

Learn more biomedcentral.com/submissions 